\title{
Catalytic Pyrolysis of High Density Polyethylene (HDPE) and Polystyrene Plastic Waste Using Zeolite Catalyst to Produce Liquid Fuel
}

\author{
Zurohaina $^{1, *}$ Irawan Rusnadi ${ }^{1}$ Fatria $^{1}$ Arizal Aswan ${ }^{1}$ Rima Daniar ${ }^{1}$ \\ ${ }^{1}$ Department of Chemical Engineering, State of Polytechnic Sriwijaya \\ *Corresponding author. Email : zurohaina@polsri.ac.id
}

\begin{abstract}
This study aims to examine catalytic pyrolysis with activated natural zeolites. A pyrolysis reactor with three levels of separator as a result of development was used to study the catalytic pyrolysis of plastic waste into liquid fuel at intervals of $200-400 \mathrm{oC}$ and operating time of 30-90 minutes. As the object, a mixture of plastic bottles of highdensity polyethylene (HDPE) and polystyrene (Styrofoam) was used, sized 5-10 mm2

The results showed that the application of 3 levels of separator and Zeolite ZAA as a catalyst in the catalytic conversion of a mixture of polyethylene and polystyrene (Styrofoam) had the effect of shortening the reaction time and increasing the production of oil yield. Physiochemical studies of all fractions showed that the fractions concerned had gasoline properties, kerosene or diesel. The composition of the fractions produced by the top, medium and bottom separator showed an increase in the percentage of heavier hydrocarbons that tended to go to the bottom separator. At the optimal reaction temperature conditions of $350 \mathrm{oC}$ for 90 minutes, a range of gasoline (C5-C10) hydrocarbons was produced at $55.17 \%$ in the top separator with a total conversion of $97.20 \%$.

This study contributes significantly to increasing knowledge about the feasibility of catalytic pyrolysis for the conversion of plastic waste into liquid fuel for people who do plastic waste processing industries in potential areas.
\end{abstract}

Keywords: Pyrolysis, Zeolite ZAA, Polystyrene, HDPE, Separator

\section{INTRODUCTION}

Plastics become an environmental problem when used and discarded, as they remain in the environment for longer periods of time due to their nonbiodegradable nature or very slow degradation [2]. Disposal of plastic waste in landfills causes environmental and operational problems [9].

Plastic waste management is carried out using a variety of methods, including reduction, reuse, incineration, energy recovery and mechanical recycling. Conventional mechanical recycling methods such as sorting, milling, washing and extrusion can only recycle $15-20 \%$ of all plastic waste. [3] Open burning or uncontrolled burning or stockpiling of plastic waste causes air, water and soil pollution [4-11].

Pyrolysis, as one of the WTE technologies, is used to convert plastic waste into energy (liquid oil) and value- added products (charcoal and gas) [14]. Pyrolysis is atertiary recycling technique in which plastic polymers are broken down into smaller organic molecules (monomers) in the absence of oxygen at high temperatures $\left(>400^{\circ}\right.$

C) [14-6]. Most of the pyrolysis studies concluded that the optimal temperature range for plastic waste pyrolysis is between 450 and $550^{\circ} \mathrm{C}$ [13]. Pyrolysis of all types of plastic waste is possible except for PET and $\mathrm{PVC}$, as it can cause corrosion problems and pipe clogging [11]. The products resulting from the abovementioned method of breaking the polymer chains generally produce about $70-80 \%$ liquid, $5-10 \%$ gas, solid residue and contaminants [15]. The liquid product contains naphtha and other components with a boiling point of 36-2700C which has the potential to be reprocessed into a fraction of higher economic value such as gasoline [4]

This study aims to examine catalytic pyrolysis with activated natural zeolites. A reactor with three levels of 
separator is used to carry out catalytic pyrolysis of mixed high-density polyethylene (HDPE) and polystyrene (PS) plastic waste into liquid fuel using Zeolite ZAA as a

catalyst [1-10]. This research contributes significantly to increasing knowledge about the feasibility of pyrolysis, providing an opportunity for the recycling sector to deploy take-off systems, in a circular economy.

\section{MATERIAL AND METHODS}

\subsection{Feedstock preparation and reactor start-up}

The raw material for high-density polyethylene (HDPE) and polystyrene (PS) plastic waste before use, is reduced in size first through a grinding process to a size of 5 to $10 \mathrm{~mm} 2$ in order to obtain a homogeneous mixture for the reactor. After the raw material is taken as needed the instrument is heated to an operating temperature of 200 - 400 oC for 60 minutes [12]. Diesel oil is used as a burner fuel to heat the reactor. Zeolite active Plus (25 kg pack) is used as a catalyst [1]. In the reactor, the temperature was measured, accurately and indirectly, by means of thermal expansion of the metallic screw conveyor. Oxygen concentration was measured by several detectors installed at the feed hopper, condenser inlet and booster outlet. Normalized system's operation was monitored and verified from pressure measurements. Any hardware failures occurred, were identified in form of pressure drops (mbars)

\subsection{Experimental Setup}

Pyrolysis is carried out using a set of reactors equipped with three separator levels which function to separate heavy and light oil fractions. On the inside of the reactor which is in the form of a vertical cylinder, there is an iron filter adsorbent coating which is useful for capturing the wax that evaporates and dissolves in the liquid oil resulting from pyrolysis. The volatile oil resulting from pyrolysis is passed through a triple separator to separate heavy and light fractions, then this product is condensed through a condenser. The raw material used is a mixture of HDPE and PS plastic waste with a ratio of $1: 1$. The reactor is a closed system, and all experiments were carried out in an oxygen free environment. The reactor has a raw material storage capacity of 20 liters, and the temperature can be raised to $800 \mathrm{oC}$. The condensed liquid oil was collected and purified using bentonite adsorbent.

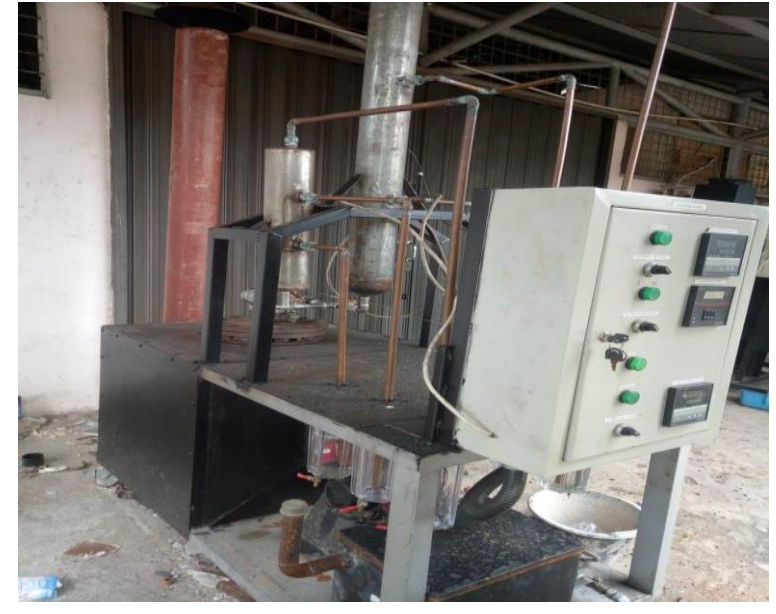

Figure 1 Catalytic Pyrolysis Reactor

\subsection{Analytical Methods}

The liquid oil produced by pyrolysis from highdensity polyethylene (HDPE) and polystyrene plastic waste was characterized using different instruments, including gas chromatography combined with mass spectrophotometry (GC-MS), Fourier transform infrared spectroscopy (FT-IR), TGA (Mettler Toledo TGA / SDTA851), USA) and Bomb Calorimeter follow the ASTM D-1298, ASTM D-86, ASTM D-445, ASTM D6304, and ASTM D-97 methods.

\section{RESULTS AND DISCUSSION}

\subsection{Effect of Temperature on Product Distribution}

The degradation reaction was carried out for 60 minutes at each temperature. Effect of temperature on the distribution of products from thermal degradation of plastic waste

HDPE and PS waste mixtures, using a pyrolysis reactor with three separator levels are given in Figure 2 Operating temperature is in the range $200 \mathrm{oC}$ to $400 \mathrm{oC}$. The degradation reaction is a batch type and each reaction is carried out for one hour at each temperature. The degradation begins at $200 \mathrm{oC}$ and increases significantly when the temperature increases from 300 oC. to 350 oC. Gas yield increases with increasing temperature up to $350 \mathrm{oC}$. and almost remains constant up to $400 \mathrm{oC}$. Oil production starts at $200 \mathrm{oC}$. and increases with temperatures up to $400 \mathrm{oC}$. Total conversion $(94.12 \%)$ at $350 \mathrm{oC}$. proportional to the total conversion $(95.20 \%)$ at $400 \mathrm{oC}$. Figure 2 shows the distribution of selectivity products for gas, oil and wax, relatively constant from $350 \mathrm{oC}$. up to $400 \mathrm{oC}$. A related result was found by Aguado et al. [1] during the degradation of waste HDPE in the presence of an acid catalyst (ZSM-5) using TGA. It is known that without a catalyst the degradation starts 
at $428^{\circ} \mathrm{C}$ and finishes at $479^{\circ} \mathrm{C}$ and in the presence of the Zeolite ZAA catalyst the reaction starts at $200 \mathrm{oC}$ and finishes at $400^{\circ} \mathrm{C}$.

The product of interest (oil) was $94.12 \%$ at $350^{\circ} \mathrm{C}$ which is comparable to $95.20 \%$ oil yield obtained at $400^{\circ} \mathrm{C}$. Thus the temperature increases beyond $350^{\circ} \mathrm{C}$ has no significant effect on product distribution? Therefore, a temperature of $350^{\circ} \mathrm{C}$ is used for degradation of plastic waste using this reactor.

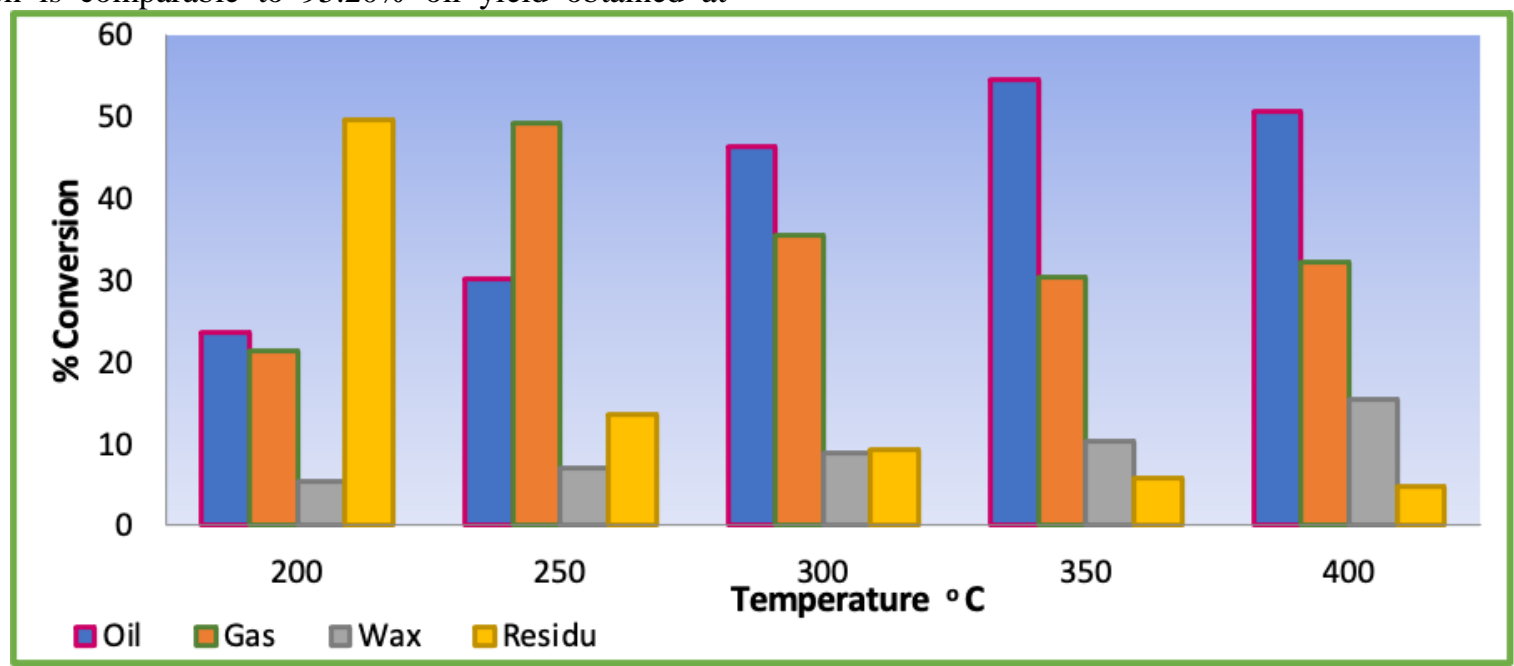

Figure 2 Effect of Reaction Temperature on Product Distribution

\subsection{Effect of Reaction Time on Optimum Temperature}

The effect of reaction time was observed at the optimum temperature of $350{ }^{\circ} \mathrm{C}$. The reaction time was carefully observed, starting from 30 minutes to 150 minutes with a time interval of every 30 minutes. The results of the observations are shown in Figure 3. The pyrolysis reaction was carried out for different time periods to determine the effect of the reaction time on the reaction product at the optimum temperature $\left(350^{\circ} \mathrm{C}\right)$. Observations were made with reaction times ranging from 30 minutes to 150 minutes with 30 minute intervals under optimal reaction conditions (Figure 3). The yield of oil at the reaction time of 30 minutes was $41.40 \%$ which gradually increased to $55.17 \%$ at the reaction time of 90 minutes. Outside the reaction time of 90 minutes, there is no significant change. Thus, a reaction time of 90 minutes is considered optimal for the degradation of HDPE and PS mixtures at an optimal temperature of $350{ }^{\circ} \mathrm{C}$.

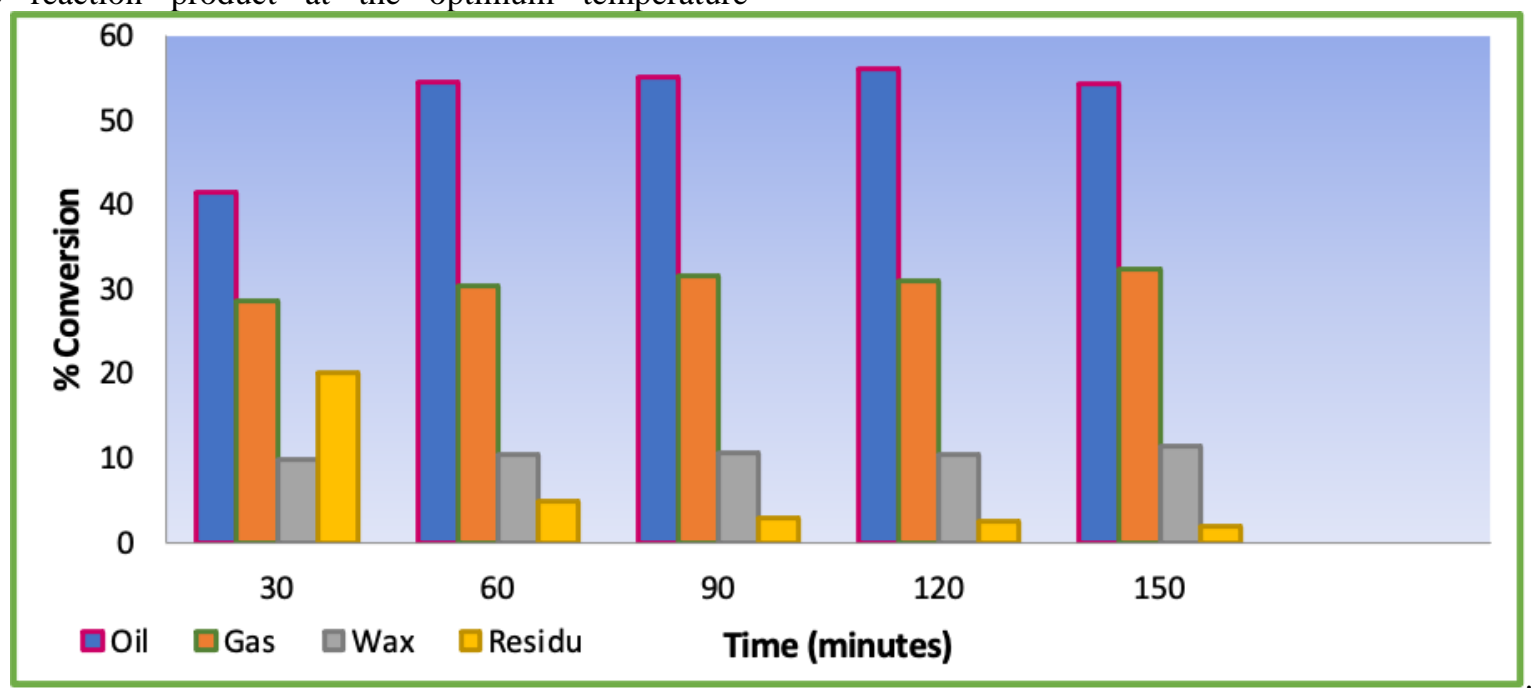

Figure 3 Effect of Reaction Time on Product Distribution 


\subsection{Pyrolysis Oil Characteristic}

The oil product resulting from the optimum reaction conditions is studied from a fuel point of view and several physicochemical tests are carried out for this purpose. The results of the experiments carried out for the oil fractions of the 3 separator levels (top, middle and bottom) were compared with standard values for gasoline, kerosene and diesel oil. Physical parameters, namely Refractive In-dex, Density, Specific gravity,
API Gravity, Viscosity, Kinematic Vis-cosity, Flash Point, Pour Point, ASTM BP range and Calorific value were determined for catalytic mother oil and its fraction. It has been observed that almost all the values of the fraction determined are practically comparable to gasoline, kerosene or diesel oil. Comparison of the observed physical parameters of the catalytic oil from each separator level is given in Table 1

\begin{tabular}{|c|c|c|c|c|c|c|}
\hline \multirow[t]{2}{*}{$\begin{array}{c}\text { Physical } \\
\text { Properties }\end{array}$} & \multicolumn{3}{|c|}{$\begin{array}{c}\text { Oil fraction of } 3 \text { levels of } \\
\text { Separator }\end{array}$} & \multicolumn{3}{|c|}{ Standard Value } \\
\hline & Top & Medium & Bottom & Gasoline & Kerosene & Diesel \\
\hline Refractive index & 1.408 & 1.430 & 1.454 & 1.434 & 1.440 & 1.484 \\
\hline Density (g/ml) & 0.731 & 0.82 & 0.81 & $0.720-0.736$ & $0.78-0.82$ & $0.83-0.85$ \\
\hline Specific gravity & 0.733 & 0.783 & 0.813 & $0.72-0.73$ & $0.78-0.82$ & $\begin{array}{l}0.83-0.85 \\
38.98-\end{array}$ \\
\hline $\begin{array}{l}\text { API gravity } \\
\text { Viscosity }\end{array}$ & 61.46 & 48.90 & 35.24 & $65.03-62.34$ & $49.91-41.06$ & 34.97 \\
\hline $\begin{array}{l}\text { (Centipoise) } \\
\text { Kinematic }\end{array}$ & 0.737 & 1.92 & 2.25 & $0.775-0.839$ & $1.2-1.8$ & $2.0-4.5$ \\
\hline $\operatorname{viscosity}\left(\mathrm{mm}^{2} / \mathrm{Sec}\right)$ & 1.135 & 1.55 & 2.607 & $1.076-1.140$ & $1.54-2.20$ & $2.4-5.3$ \\
\hline Flash point (LC) & 35.8 & 60 & 60.97 & $37.8-38$ & $50-55$ & $55-60$ \\
\hline $\begin{array}{l}\text { Pour point (LC) } \\
\text { ASTM BP }\end{array}$ & - & - & - & - & - & - \\
\hline Range(LC) & - & - & - & $40-205$ & $175-325$ & $150-350$ \\
\hline Cal. value (MJ/kg) & 45.8 & 45.4 & 42.1 & 46.9 & 45.5 & 43.7 \\
\hline
\end{tabular}

\section{CONCLUSION}

The pyrolysis reactor which is equipped with 3 levels of separator and Zeolite ZAA as a catalyst in the catalytic conversion of a mixture of high-density polyethylene (HDPE) and polystyrene (PS) has the effect of shortening reaction times and increasing oil yield. Physio-chemical studies of all fractions show that the fractions concerned have the properties of gasoline, kerosene or diesel.

The composition of the fractions produced by the top, medium and bottom separator showed an increase in the percentage of heavier hydrocarbons that tended to go to the bottom separator. At the optimum reaction temperature conditions of $350{ }^{\circ} \mathrm{C}$ and time of 60 minutes, a range of gasoline ( $\mathrm{C} 5-\mathrm{C} 10)$ hydrocarbons of $55.17 \%$ was produced in the top separator with a total conversion of $97.20 \%$.

\section{REFERENCES}

[1] Aguado J, Serrano DP, San Miguel G, Escola JM, Rodrıguez JM. Catalytic activity of zeolitic and mesostructured catalysts in the cracking of pure and waste polyolefins. J Anal Appl Pyrol 2007;78:153-61.
[2] Achilias DS, Roupakias C, Megalokonomos P, Lappas AA, Antonakou EV (2007) Chemical recycling of plastic waste made from polyethylene (LDPE and HDPE) and polypropylene (PP). J Hazard Mater 149:536-542

[3] Ashworth DC, Elliott P, Toledano MB (2014) Waste incineration and adverse birth and neonatal outcomes: a systematic review. Environ Int 69:120-132

[4] Buekens AG, Huang H (1998) Catalytic plastics cracking for recovery of gasoline- range hydrocarbons from municipal plastic wastes. Resour Conserv Recycl 23:163-181

[5] Chen C, Jin Y, Chi Y (2014a) Effects of moisture content and $\mathrm{CaO}$ on municipal solid waste pyrolysis in a fixed bed reactor. J Anal Appl Pyrol 110:108-112

[6] Chen D, Yin L, Wang H, He P (2014b) Pyrolysis technologies for municipal solid waste: a review. Waste Manag 34:2466-2486

[7] Jan MR, Shah J, Gulab H. Degradation of waste high-density polyethylene into fuel oil using basic catalyst. Fuel 2010;89:474-80. 
[8] Gobin K, Manos G. Thermogravimetric study of polymer catalytic degradation over microporous materials. Polym Degrad Stab 2004;86:225-31.

[9] Khan MS, Kaneesamkandi Z (2013) Biodegradable waste to biogas: renewable energy option for the Kingdom of Saudi Arabia. Int J Innov Appl Stud 4(1):101-113

[10] Lin YH, Yang MH, Yeh TF, Ger MD. Catalytic degradation of high density polyethylene over mesoporous and microporous catalysts in a fluidized-bed reactor. Polym Degrad Stab 2004;86:121-8.

[11] Lopez A, Marco ID, Caballero BM, Laresgoiti MF, Adrados A (2012) Catalytic stepwise pyrolysis of packaging plastic waste. J Anal Appl Pyrol 96:54$62 d$

[12]M. Rasul Jan, Jasmin Shah , Hussain Gulab "Catalytic conversion of waste high-density polyethylene into useful hydrocarbons" Fuel 105 (2013) 595-602

[13] N. Antoniou, A. Zabaniotou* Re-designing a viable ELTs depolymerization in circular economy: Pyrolysis prototype demonstration at TRL 7, with energy optimization and carbonaceous materials production" Journal of Cleaner Production 174 (2018) $74 \mathrm{e} 86$

[14] Sharma BK, Moser BR, Vermillion KE, Doll KM, Rajagopalan N (2014) Production, characterization and fuel properties of alternative diesel fuel from pyrolysis of waste plastic grocery bags. Fuel Process Technol 122:79-90

[15]Witold M. Lewandowskia,*, Katarzyna Januszewicza, Wojciech Kosakowskib "Efficiency and proportions of waste tyre pyrolysis products depending on the reactor type-A review" Journal of Analytical and Applied Pyrolysis 140 (2019) $25-53$ 